\title{
Using Three-Level Fuzzy Space Vector Modulation Method to Improve Indirect Vector Control Strategy of a DFIG Based Wind Energy Conversion Systems
}

\author{
Habib Benbouhenni*, Zinelaabidine Boudjema**, Abdelkader Belaidi* \\ *National Polytechnique School of Oran Maurice Audin, Oran, Algeria \\ ** Electrical Engineering Departement, Faculty of Technology, Hassiba Benbouali University, Chlef, Algeria. \\ (habib0264@gmail.com, boudjemaa1983@yahoo.fr, belaidiaek@gmail.com) \\ ${ }^{\ddagger}$ Corresponding Author; Habib Benbouhenni, BP: 50B Ouled Fares Chlef, Algeria, Tel: +213663956329, \\ habib0264@gmail.com
}

Received: 30.06.2018 Accepted:29.08.2018

\begin{abstract}
This work present a Indirect Vector Command (IVC) method with three-level space vector modulation (SVM) and Fuzzy regulator (FR) of a doubly fed induction generator (DFIG) incorporated in a wind turbine system (WTS). Classical IVC command technique using three-level SVM inverter presents considerable stator reactive and stator active powers ripples at fixed state period. In order to guaranteed a strong IVC strategy for the DFIG-rotor side converter and decrease stator active and stator reactive powers ripples, a three-level SVM inverter strategy based on fuzzy logic regulator (FSVM) is used in this work. Simulation results show the competence of the proposed strategy of command particularly on the quality of the provided energy comparatively to a classical IVC using SVM inverter.
\end{abstract}

Keywords: Doubly fed induction generator, indirect vector command, three-level space vector modulation, fuzzy controller, fuzzy space vector modulation, wind turbine system.

\section{Introduction}

The WT has become the fastest growing renewable power source in the word. This is mainly due to the fact that it has received a thorough interest and has been considered as a way of fighting climate change command of the speed of the WTS is generally used to improve the energy fabrication [1].

Since, the DFIG is one of the most popular variable speeds WT in use nowadays. It is usually fed by a electrical energy source converter [2]. Traditionally, command of DFIG wind turbine systems is achieved by vector command (VC) based on either stator flux oriented command (FOC) or stator voltage oriented command (VOC). These techniques decouple the rotor currents into reactive power and active power components; command of the stator active and stator reactive powers is achieved indirectly by controlling the input currents [3]. Some investigations using classical PI regulators that generate references stator currents from stator reactive and stator active powers errors to the converter or cascade PI regulators that generate a rotor energy which has been presented by [4].

On the other hand, multilevel inverter which was proposed by Nabae [5]. Economic three basic multilevel inverters are presented in the literature as diode-clamped inverters cascaded H-bridge inverters and flying-capacitor inverters [6]. The neutral point clamped topology (NPC) is mainly used one. The main intended of these converters is to use diodes to limit the energy devices electrical energy stress [7].

Since, the SPWM (sinusoidal pulse width modulation) method is widely used in changeable speed drive of induction machine, especially for scalar command (SC) where the stator electrical energy and frequency can be regulated with minimum online computational requirement. However, this strategy is easy to implement. On the other 
hand, this technique has the following drawbacks. This method is unable to fully utilize the available DC bus supply voltage to the VSI. This method gives more total harmonic distortion (THD), this modulation strategy does not smooth the progress of future development of VC implementation of AC drive. These drawbacks lead to development of a sophisticated PWM algorithm which is SVM strategy. The SVM gives $15 \%$ more voltage output compare to the classical PWM technique [8]. On the other hand, SVM inverter fed a DFIG of electrical drives has become an attracting theme in research and school over the past decade. Lik an every command technique has several disadvantages and advantages [9]. In the aim to improve the performance of the DFIG based on classical IVC method using SVM inverter, fuzzy space vector modulation (FSVM) it used in this work to improve the stator active power and stator reactive powers ripples and minimize the THD value of current.

\section{Model of Turbine}

The WT input power usually is [10]:

$$
P_{v}=0.5 \rho S_{w} v^{3}
$$

Where $\rho$ is air density, $S_{w}$ is WT blades swept area in the wind, $\mathrm{v}$ is wind speed.

The output mechanical power of WT is:

$$
P_{m}=C_{p} \cdot P_{v}=0.5 \rho \cdot C_{p} \cdot S_{w} v^{3}
$$

Where $C_{p}$ represents the WT energy conversion efficiency. It is a function of the tip speed ratio $\lambda$ and the blade pitch angle $\beta$ in a pitch-controlled WT. $\lambda$ is defined as the ration of the tip speed of the turbine blades to wind speed :

$$
\lambda=\frac{R \cdot \Omega_{t}}{v}
$$

Where $\mathrm{R}$ is blade radius. $\Omega$ is angular speed of the turbine. $\mathrm{C}_{\mathrm{p}}$ can be described as $[11,12]$ :

$$
\begin{aligned}
& C_{p}(\beta, \lambda)=C_{1} \cdot\left(\frac{C_{2}}{\lambda_{i}}-C_{3 .} \beta-C_{4}\right) \cdot \exp \left(\frac{-C_{5}}{\lambda_{i}}\right)+C_{6} \cdot \lambda \\
& \frac{1}{\lambda_{i}}=\frac{1}{\lambda+0.08 \cdot \beta}-\frac{0.035}{\beta^{3}+1}
\end{aligned}
$$

The electromagnetic torque produced by the turbine is expressed in the following way [13]:

$$
T_{t}=\frac{P_{t}}{\Omega_{t}}=0.5 \rho \cdot \pi \cdot R^{3} \cdot v^{2} \cdot C_{t}
$$

Where, $\mathrm{Ct}$ is the torque coefficient expressed by :

$$
C_{t}=\frac{C_{p}}{\lambda}
$$

\section{Modeling of the DFIG}

The universal electrical state representation of the DFIG obtained with Park alteration is given by the following equations $[14,15]$ :

Rotor voltage and stator voltage:

$\left\{\begin{array}{l}\mathrm{V}_{\mathrm{ds}}=\mathrm{R}_{\mathrm{s}} \mathrm{I}_{\mathrm{ds}}+\frac{\mathrm{d}}{\mathrm{dt}} \psi_{\mathrm{ds}}-\omega_{\mathrm{s}} \psi_{\mathrm{qs}} \\ \mathrm{V}_{\mathrm{qs}}=\mathrm{R}_{\mathrm{s}} \mathrm{I}_{\mathrm{qs}}+\frac{\mathrm{d}}{\mathrm{dt}} \psi_{\mathrm{qs}}+\omega_{\mathrm{s}} \psi_{\mathrm{ds}} \\ \mathrm{V}_{\mathrm{dr}}=\mathrm{R}_{\mathrm{r}} \mathrm{I}_{\mathrm{dr}}+\frac{\mathrm{d}}{\mathrm{dt}} \psi_{\mathrm{dr}}-\omega_{\mathrm{r}} \psi_{\mathrm{qr}} \\ \mathrm{V}_{\mathrm{qr}}=\mathrm{R}_{\mathrm{r}} \mathrm{I}_{\mathrm{qr}}+\frac{\mathrm{d}}{\mathrm{dt}} \psi_{\mathrm{qr}}+\omega_{\mathrm{r}} \psi_{\mathrm{dr}}\end{array}\right.$

Stator and rotor fluxes:

$\left\{\begin{array}{l}\psi_{d s}=L_{s} I_{d s}+M I_{d r} \\ \psi_{q s}=L_{s} I_{q s}+M I_{q r} \\ \psi_{d r}=L_{r} I_{d r}+M I_{d s} \\ \psi_{q r}=L_{r} I_{q r}+M I_{q s}\end{array}\right.$

Electromagnetic torque is done as:

$T_{e m}=\frac{3}{2} p \frac{M}{L_{s}}\left(\psi_{q s} I_{d r}-\psi_{d s} I_{q r}\right)$

And its associated motion equation is:

$$
T_{e m}=T_{r}+J \cdot \frac{d \Omega}{d t}+f \cdot \Omega
$$

The reactive and stator active powers are defined as:

Where, $\mathrm{C} 1=0.5176, \quad \mathrm{C} 2=116, \quad \mathrm{C} 3=0.4, \quad \mathrm{C} 4=5, \quad \mathrm{C} 5=21$, C6 $=0.0068$ 


$$
\left\{\begin{array}{l}
P_{s}=\frac{3}{2}\left(V_{d s} I_{d s}+V_{q s} I_{q s}\right) \\
Q_{s}=\frac{3}{2}\left(V_{q s} I_{d s}-V_{d s} I_{q s}\right)
\end{array}\right.
$$

\section{Space Vector Modulation for Three-level Inverter}

The topology that have been used in this paper is a three phase full bridge three levels NPC converter and the space vector diagram of this inverter is shown in Fig. 1. The space vector modulation is a good method that can be used to command the voltage converter, with less harmonic and commutation losses [16]. A novel SVM technique for a three level inverter (3LI) is proposed in this article. The principle of SVM technique is that the command voltage vector (VV) is approximately calculated by using three adjacent vectors [17].
The SVM for 3LIs can be implemented by considering the following steps:

- Calculated the min and max

- $\quad$ Find the switching states.

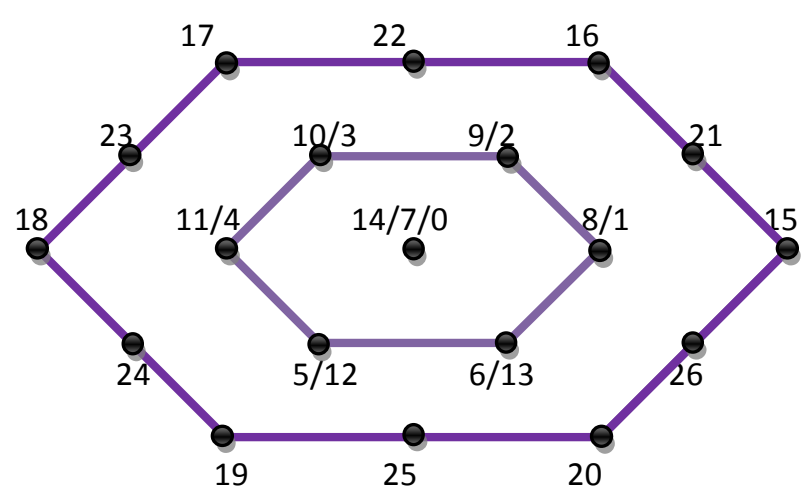

Fig. 1 Three phase voltage space vectors in the $\alpha \beta$ plane.

The block diagram of proposed SVM method for threelevel inverter is as shown in Fig. 2.

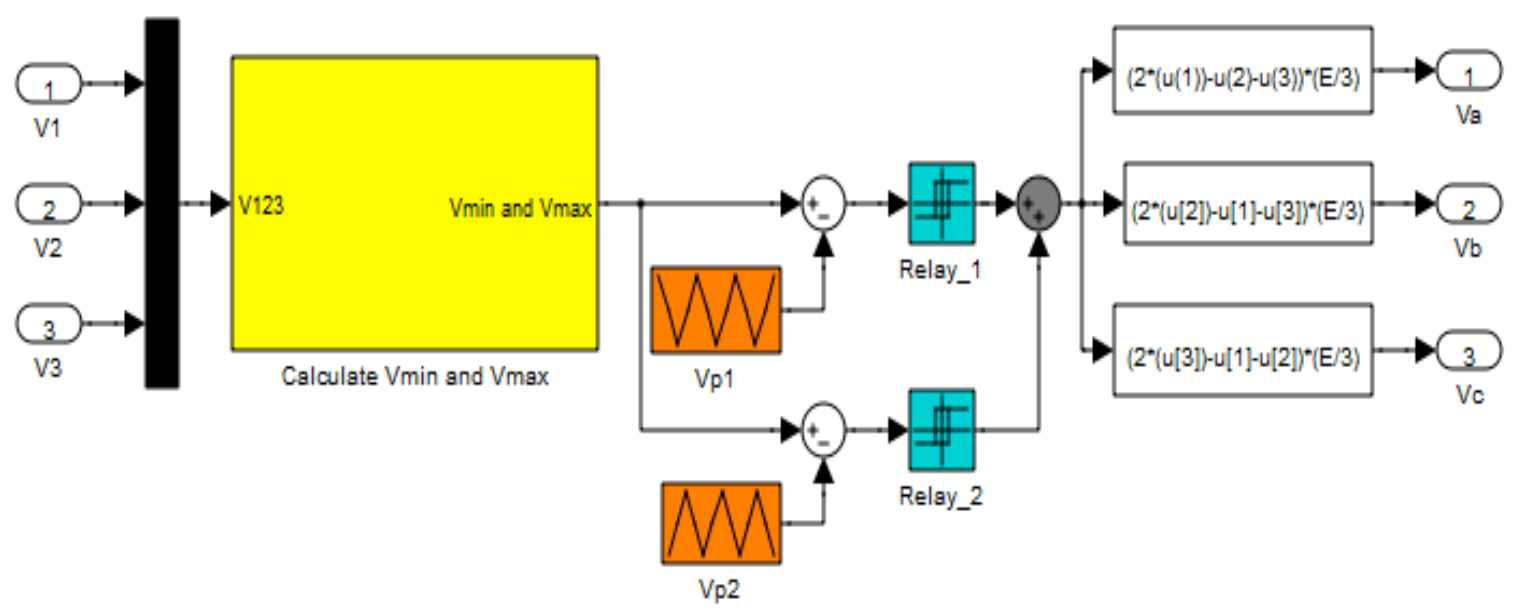

Fig. 2 SVM inverter.

\section{Vector Command by Directing the Flow Stator}

The principle is to orient the stator flux along the axis of the rotating frame

$\psi_{q s}=0, \psi_{d s}=\psi_{s}$

Machines for medium and high power used in WTs, we can neglect the stator resistance.

$\left\{\begin{array}{l}\psi_{d s}=\psi_{s}=L_{s .} I_{d s}+M . I_{d r} \\ \psi_{q s}=\psi_{s}=L_{s .} I_{q s}+M . I_{q r}\end{array}\right.$

With:

$$
\left\{\begin{array}{l}
I_{d s}=-\frac{M}{L_{s}} I_{d r}+\frac{\psi_{s}}{L_{s}} \\
I_{q s}=-\frac{M}{L_{s}} I_{q r}
\end{array}\right.
$$

$$
\left\{\begin{array}{l}
V_{d s}=0 \\
V_{q s}=\omega_{s} \psi_{s}
\end{array}\right.
$$




$$
\left\{\begin{array}{l}
\psi_{d s}=\left(L_{r}-\frac{M^{2}}{L_{s}} \cdot I_{d r}\right)+M \cdot \frac{V_{s}}{L_{s} \cdot w_{s}} \\
\psi_{q s}=\left(L_{r}-\frac{M^{2}}{L_{s}}\right) I_{q r}
\end{array}\right.
$$

$$
\left\{\begin{array}{c}
P_{s}=-V_{s} \cdot \frac{M}{L_{s}} \cdot I_{q r} \\
Q_{s}=V_{s} \cdot \frac{V_{s}^{2}}{L_{s}} \frac{M}{L_{s}} \cdot I_{d r}
\end{array}\right.
$$

The equation of reactive and active power becomes:

$$
\left\{\begin{array}{l}
P_{s}=V_{d s} \cdot I_{d s}+V_{q s} \cdot I_{q s} \\
Q_{s}=V_{q s} \cdot I_{d s}-V_{d s} \cdot I_{q s}
\end{array}\right.
$$

$$
\left\{\begin{array}{l}
V_{d r}=R_{r} \cdot I_{d r}+\left(L_{r}-\frac{M^{2}}{L_{s}}\right) p \cdot I_{d r}-g \cdot w_{s} \cdot\left(L_{r}-\frac{M^{2}}{L_{s}}\right) \cdot I_{q r} \\
V_{q r}=R_{r} \cdot I_{q r}+\left(L_{r}-\frac{M^{2}}{L_{s}}\right) \cdot p \cdot I_{q r}+g \cdot w_{s} \cdot\left(L_{r}-\frac{M^{2}}{L_{s}}\right) \cdot I_{d r}+g \cdot \frac{M \cdot V_{s}}{L_{s}}
\end{array}\right.
$$

In steady state, we can write:

$$
\begin{aligned}
& \left\{\begin{array}{l}
V_{d r}=R_{r} \cdot I_{d r}-g \cdot w_{s} \cdot\left(L_{r}-\frac{M^{2}}{L_{s}}\right) \cdot I_{q r} \\
V_{q r}=R_{r} \cdot I_{q r}+g \cdot w_{s} \cdot\left(L_{r}-\frac{M^{2}}{L_{s}}\right) \cdot I_{d r}+g \cdot \frac{M \cdot V_{s}}{L_{s}}
\end{array}\right. \\
& \left\{\begin{array}{l}
I_{d r}=\left(V_{d r}+g \cdot w_{s} \cdot\left(L_{r}-\frac{M^{2}}{L_{s}}\right) \cdot I_{q r}\right) \frac{1}{R_{r}+\left(L_{r}-\frac{M^{2}}{L_{s}}\right) p} \\
I_{q r}=\left(V_{q r}-g \cdot w_{s} \cdot\left(L_{r}-\frac{M^{2}}{L_{s}}\right) \cdot I_{d r}-g \cdot \frac{M \cdot V_{s}}{L_{s}}\right) \frac{1}{R_{r}+\left(L_{r}-\frac{M^{2}}{L_{s}}\right) p}
\end{array}\right.
\end{aligned}
$$

With: $\mathrm{V}_{\mathrm{dr}}$ and $\mathrm{V}_{\mathrm{qr}}$ : rotor voltages to impose on the machine to get the desired rotor currents.

The torque has the expression:

$T_{e}=p \frac{M}{L_{s}} I_{q r} \psi_{d s}$

Fig. 3 represents the IVC command scheme of DFIG driven by a three-level inverter using SVM technique:

The internal structure of IVC command is shown in Fig. 4.
The negative of the IVC technique is that the reactive and stator active power ripples. In order to reduce powers ripples and minimize the THD value of stator current, we propose to use the fuzzy logic (FL) regulator.

FL is recently attainment rising importance in drive command applications. Recent years, FL command has found many applications in the past two decades. This is so largely increasing because FL command has the capability to command nonlinear uncertain systems even in the case where no mathematical model is available for the command system $[18,19]$. 


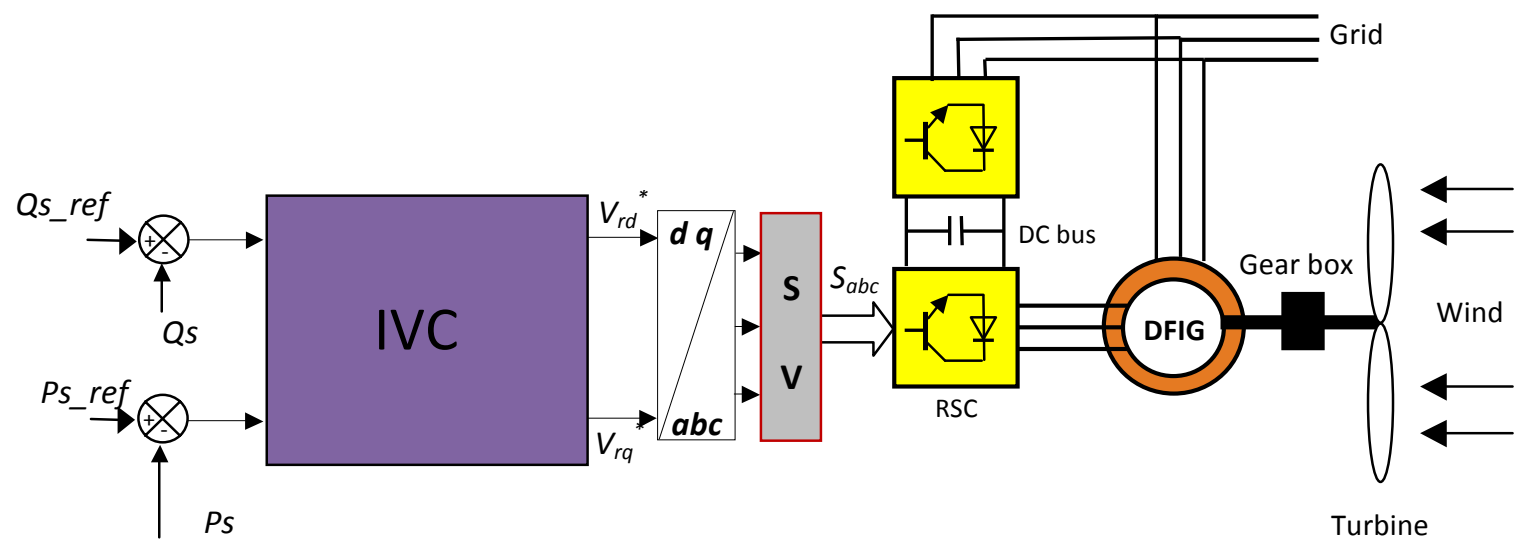

Fig. 3 IVC method block with SVM inverter.

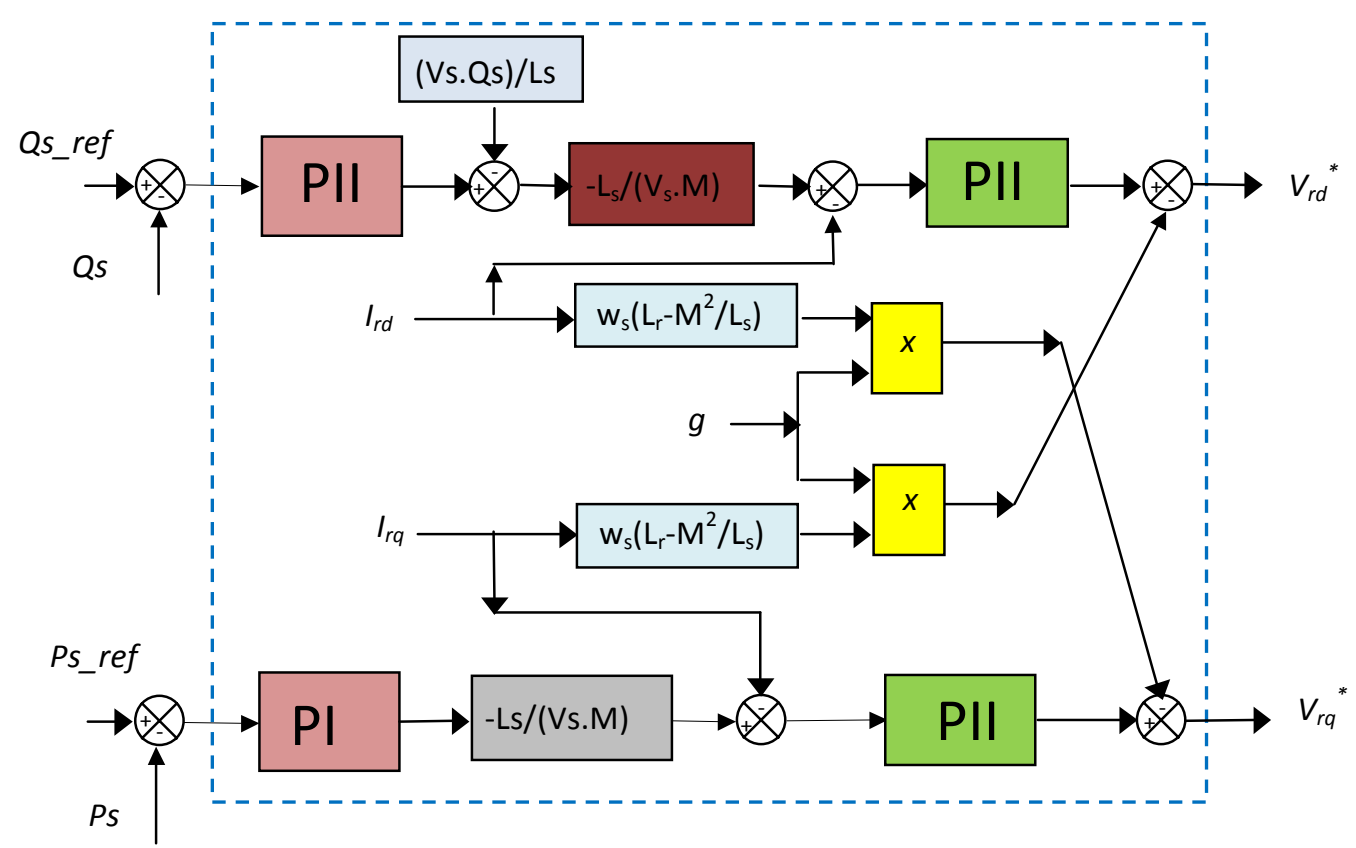

Fig. 4 Structure of IVC scheme.

The courante preference of the FL is that is simple and easy to implement command that it has the ability of generalization $[20,21]$. It is able to give a very satisfactory performance to command the grid side converter of DFIG. For the two proposed fuzzy space vector modulation (FSVM) in Fig. 5, the universes of discourses are first partitioned into the 7 linguistic variables NB, NM, NS, EZ, PS, PM, PB, triangular (Fig. 6) membership functions are chosen to represent the linguistic variables and FL singletons for the output are used.
The FL rules that produce these command initiatives are reported in Table 1. We use the following designations for membership functions:

NB : Negative Big

PB: Positive Big

PM : Positive Middle

NM : Negative Middle

NS : Negative Small

EZ : Equal Zero

PS: Positive Small 
INTERNATIONAL JOURNAL of SMART GRID

First Author et al., Vol.x, No.x, xxxx

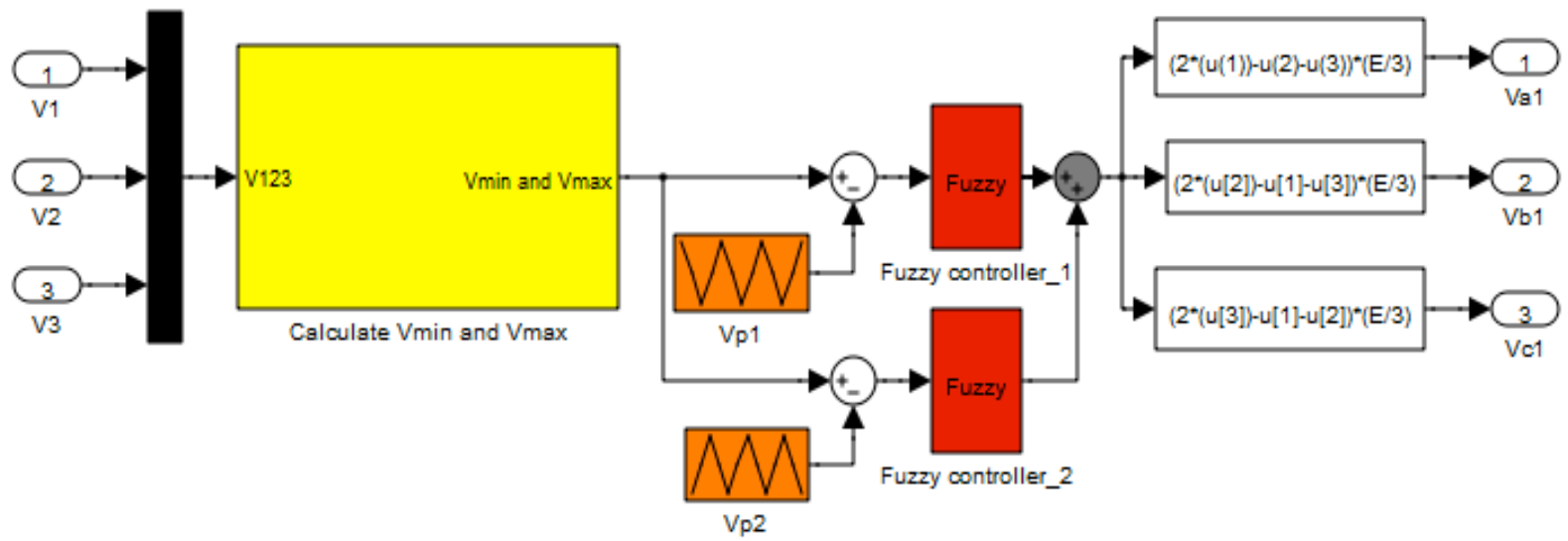

Fig. 5 Bloc diagram of the SVM technique with Fuzzy controllers (FSVM).

Table 1. Matrix of inference

\begin{tabular}{|l|l|l|l|l|l|l|l|}
\hline \multicolumn{1}{|c|}{$\mathbf{e}$} & NB & $\mathbf{N M}$ & $\mathbf{N S}$ & $\mathbf{E Z}$ & $\mathbf{P S}$ & $\mathbf{P M}$ & $\mathbf{P B}$ \\
\cline { 1 - 7 } \multicolumn{1}{|c}{} & & & & & & & \\
\hline NB & NB & NB & NB & NB & NM & NS & EZ \\
\hline NM & NB & NB & NB & NM & NS & EZ & PS \\
\hline NS & NB & NB & NM & NS & EZ & PS & PM \\
\hline EZ & NB & NM & NS & EZ & PS & PM & PB \\
\hline PS & NM & NS & EZ & PS & PM & PB & PB \\
\hline PM & NS & EZ & PS & PM & PB & PB & PB \\
\hline PB & EZ & PS & PM & PB & PB & PB & PB \\
\hline
\end{tabular}
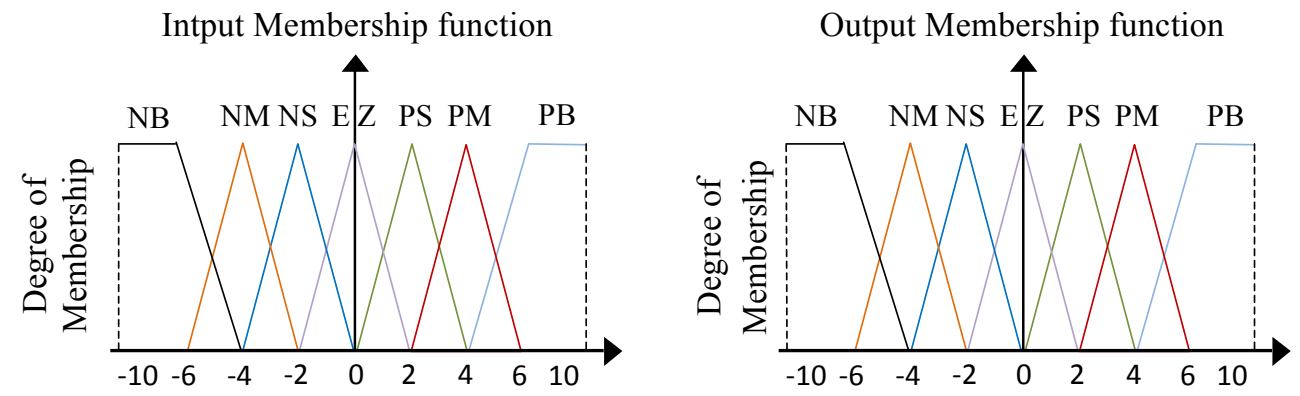

Fig. 6 FL sets and its memberships functions.

The utilized FSVM-IVC command blocks are shown in Fig. 7. 


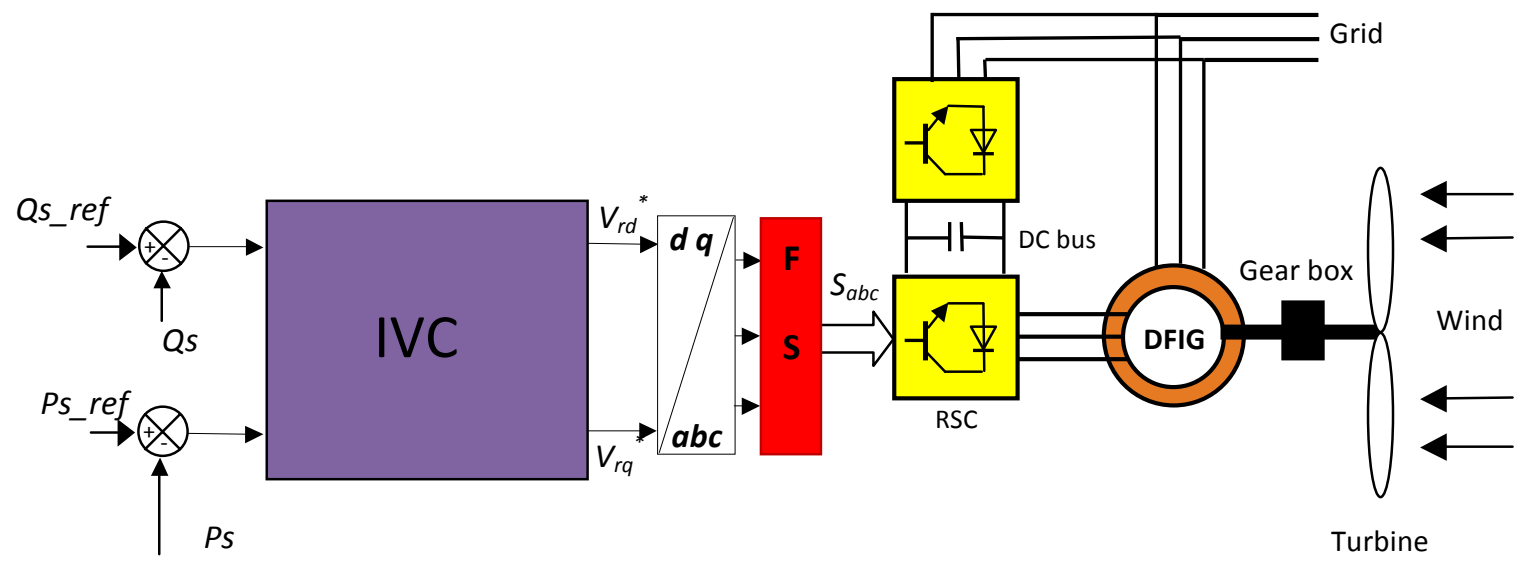

Fig. 7 IVC-FSVM command.

\section{Simulation Results}

In the objective to improve the performance of IVC command, simulation tests are realised with a $1.5 \mathrm{MW}$ generator coupled to a $398 \mathrm{~V} / 50 \mathrm{~Hz}$ grid. The DFIG parameters are given in the Table. 2. Simulation of the DFIG controlled by IVC command has been realised using Matlab/Simulink. The two IVC command strategies; SVMIVC and FSVM-IVC are simulated and compared in terms of reference tracking, stator current harmonics distortion, powers ripples and robustness against generator parameter variations.

Table 2. The DFIG parameters.

\begin{tabular}{|l|c|c|}
\hline \multicolumn{1}{|c|}{ Parameters } & Rated Value & Unity \\
\hline Nominal power & 1.5 & $\mathrm{MW}$ \\
\hline Stator voltage & 398 & $\mathrm{~V}$ \\
\hline Stator frequency & 50 & $\mathrm{~Hz}$ \\
\hline Number of pairs poles & 2 & \\
\hline Stator resistance & 0.012 & $\Omega$ \\
\hline Rotor resistance & 0.021 & $\Omega$ \\
\hline Stator inductance & 0.0137 & $\mathrm{H}$ \\
\hline Rotor inductance & 0.0136 & $\mathrm{H}$ \\
\hline Mutual inductance & 0.0135 & $\mathrm{H}$ \\
\hline Inertia & 1000 & $\mathrm{Kg} \mathrm{m}{ }^{2}$ \\
\hline Viscous friction & 0.0024 & $\mathrm{Nm} / \mathrm{s}$ \\
\hline
\end{tabular}

\subsection{Reference tracking test}

The objective of this test is to study the performance of both IVC command techniques for the doubly fed induction generator. Figs 8-12 show the obtained simulation results. As it's shown by Fig. 8, for the two IVC command with SVM and FSVM respectively, the torque, the reactive and active powers tracks almost perfectly their references values.

Fig. 12 shows the harmonic spectrums of stator current of the DFIG machine obtained using Fast Fourier Transform (FFT) strategy for both IVC command schemes. It can be clear observed that the THD is reduced for IVC-FSVM command. Table 3 show the comparative analysis of the THD value of stator current.

Table 3. Comparative analysis of THD value

\begin{tabular}{|l|c|c|}
\cline { 2 - 3 } \multicolumn{1}{c|}{} & \multicolumn{2}{c|}{ THD (\%) } \\
\cline { 2 - 3 } \multicolumn{1}{c|}{} & IVC-SVM & IVC-FSVM \\
\hline Stator current & 1.34 & $\mathbf{0 . 0 4}$ \\
\hline
\end{tabular}

Figs. 13-16 show the zoom in the reactive power, active power, electromagnetic torque and current of the IVC-SVM and IVC-FSVM command schemes. This figure shows that the ripple of reactive power, active powers, electromagnetic torque and stator current in the IVC-FSVM command scheme has been zero. 
INTERNATIONAL JOURNAL Of SMART GRID

First Author et al., Vol.x, No.x, xxxx

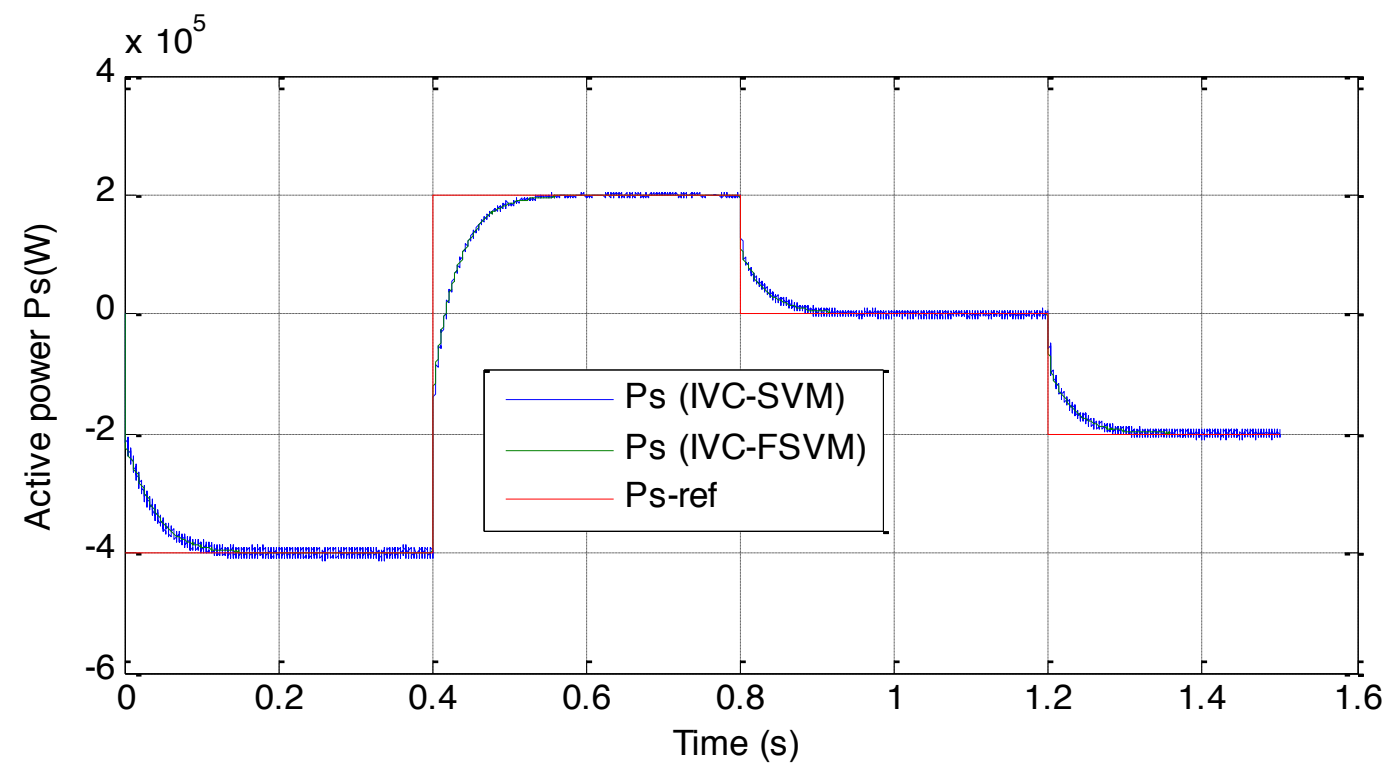

Fig. 8 Active power (reference tracking test).

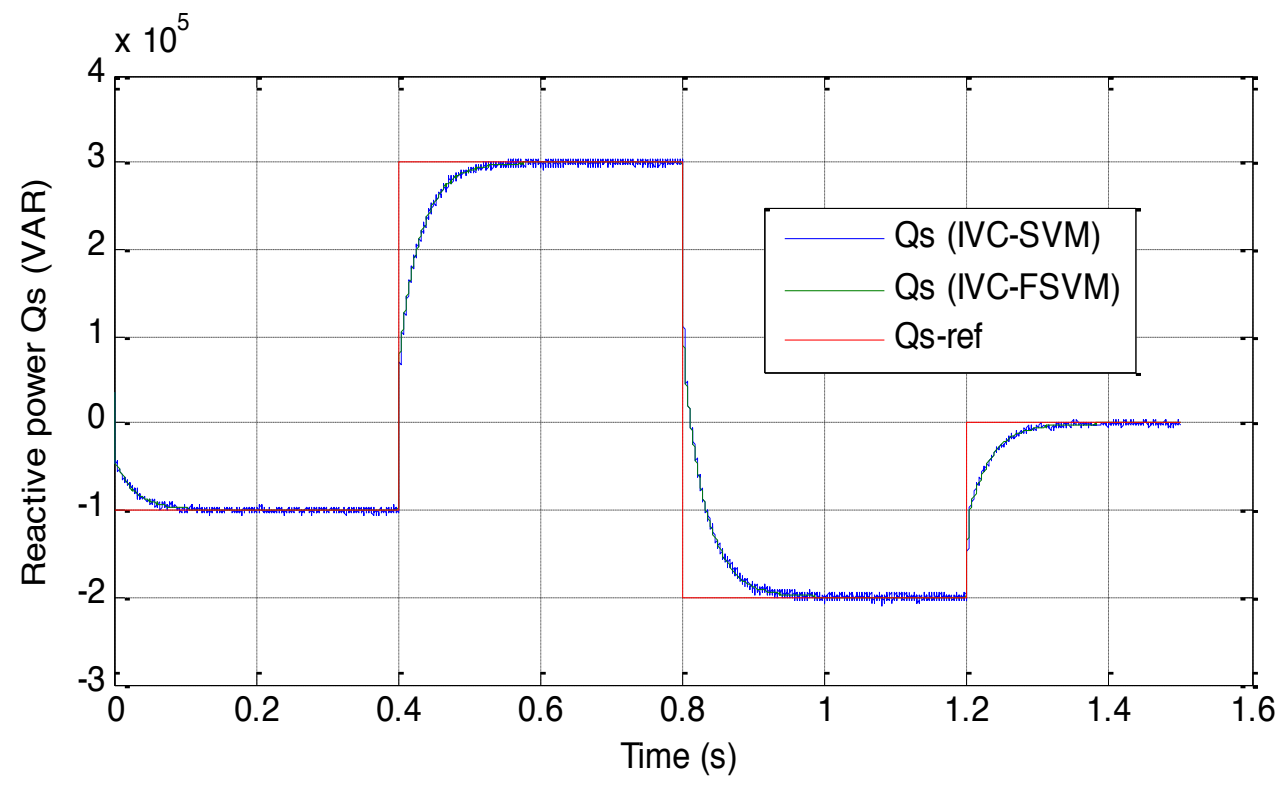

Fig. 9 Reactive power (reference tracking test). 
INTERNATIONAL JOURNAL Of SMART GRID

First Author et al., Vol.x, No.x, xxxx

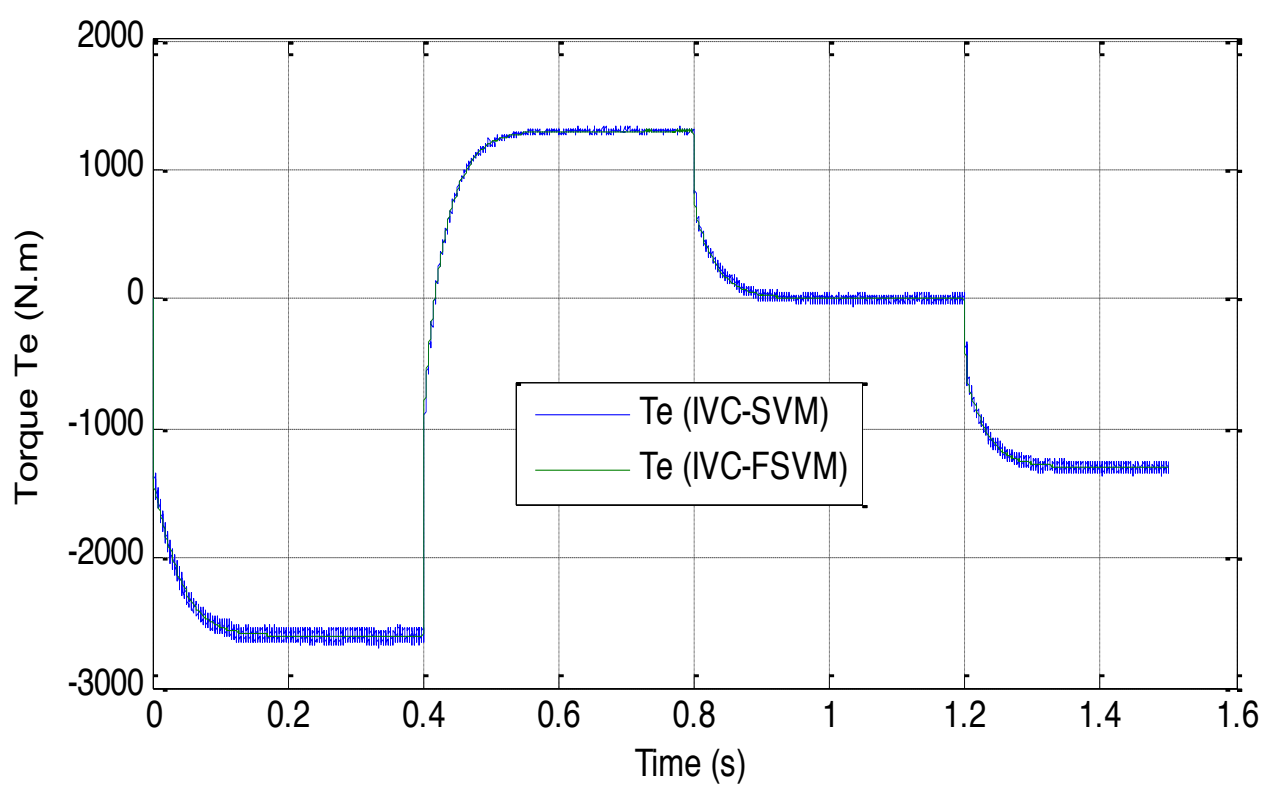

Fig. 10 Electromagnetique torque (reference tracking test).

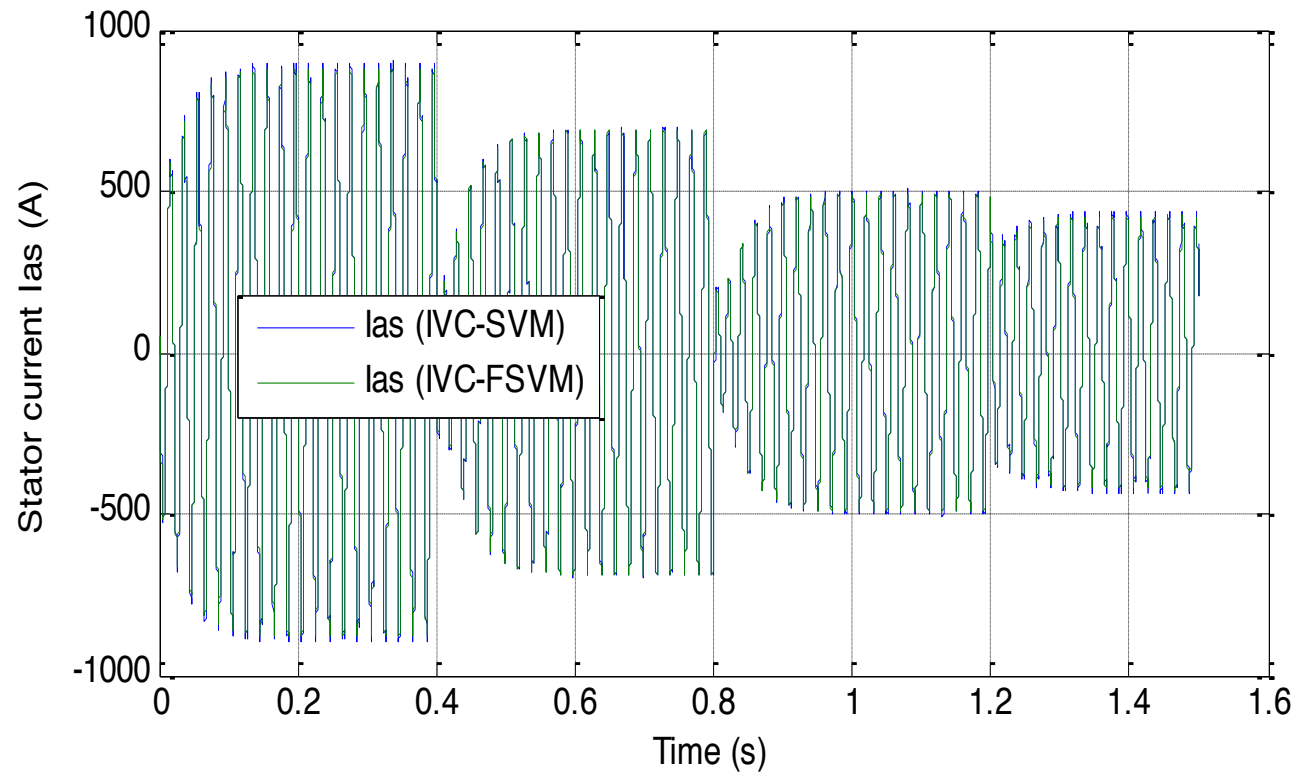

Fig. 11 Stator current (reference tracking test). 
INTERNATIONAL JOURNAL OF SMART GRID

First Author et al., Vol.x, No.x, xxxx
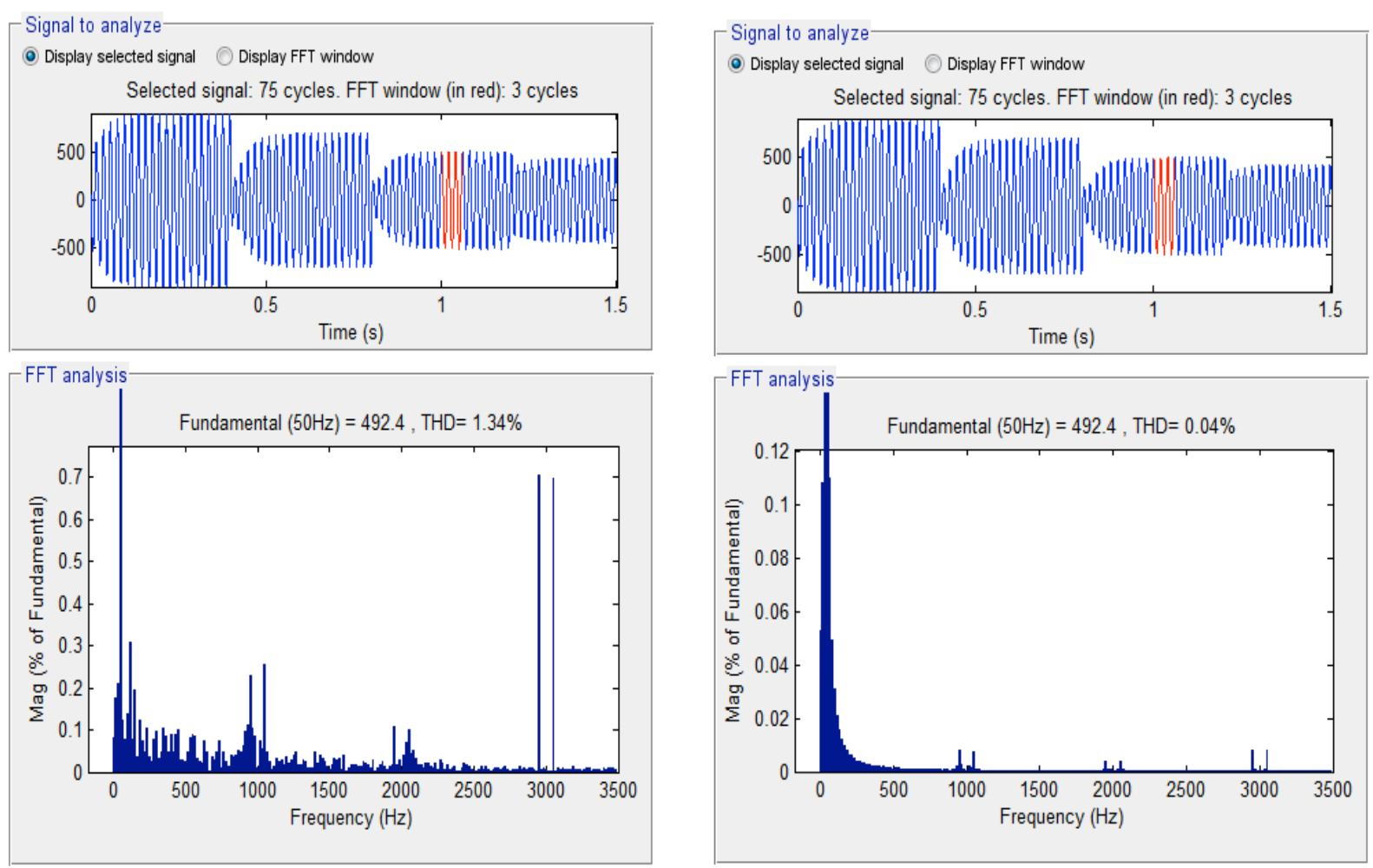

a)SVM-IVC

b) FSVM-IVC

Fig. 12 THD of one phase stator current for a DFIG (reference tracking test).

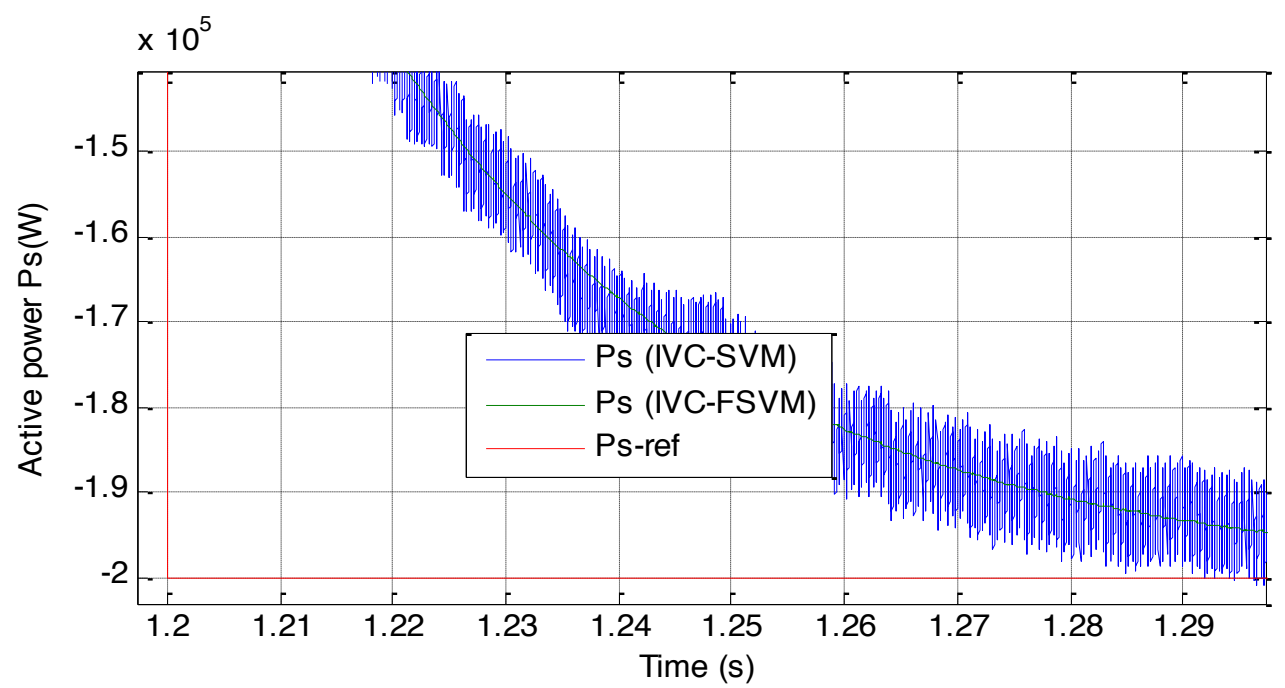

Fig. 13 Zoom in the active power (reference tracking test). 
INTERNATIONAL JOURNAL of SMART GRID

First Author et al., Vol.x, No.x, xxxx

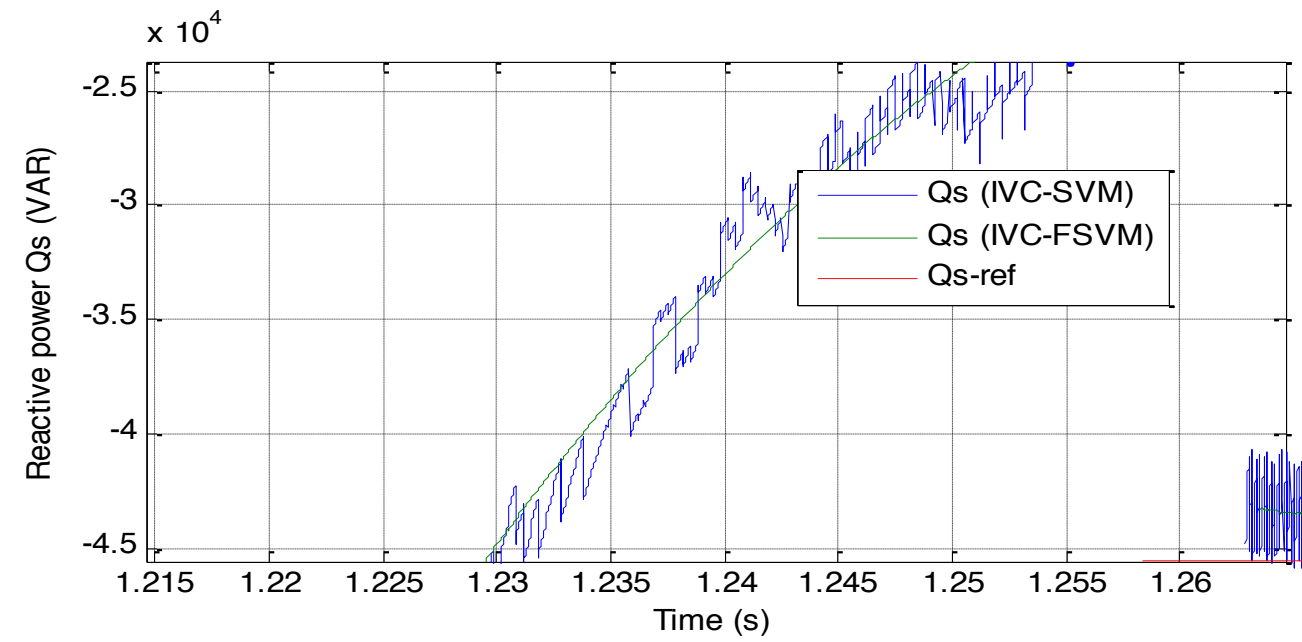

Fig. 14 Zoom in the reactive power (reference tracking test).

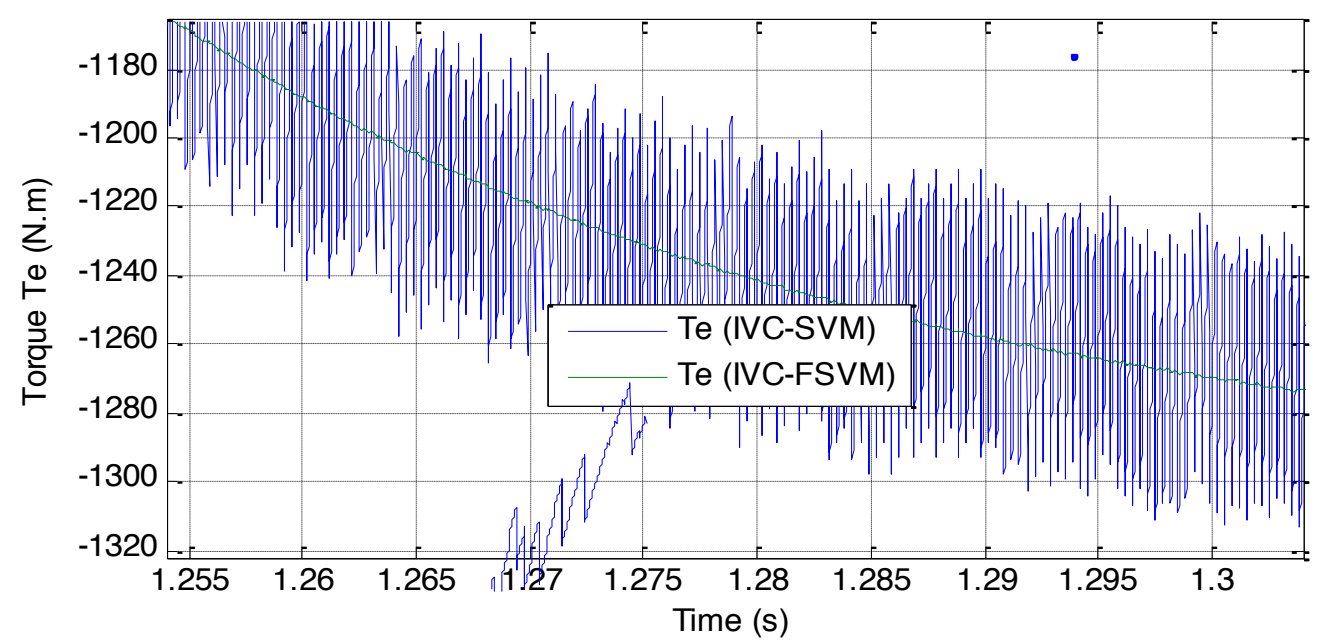

Fig. 15 Zoom in the torque (reference tracking test).

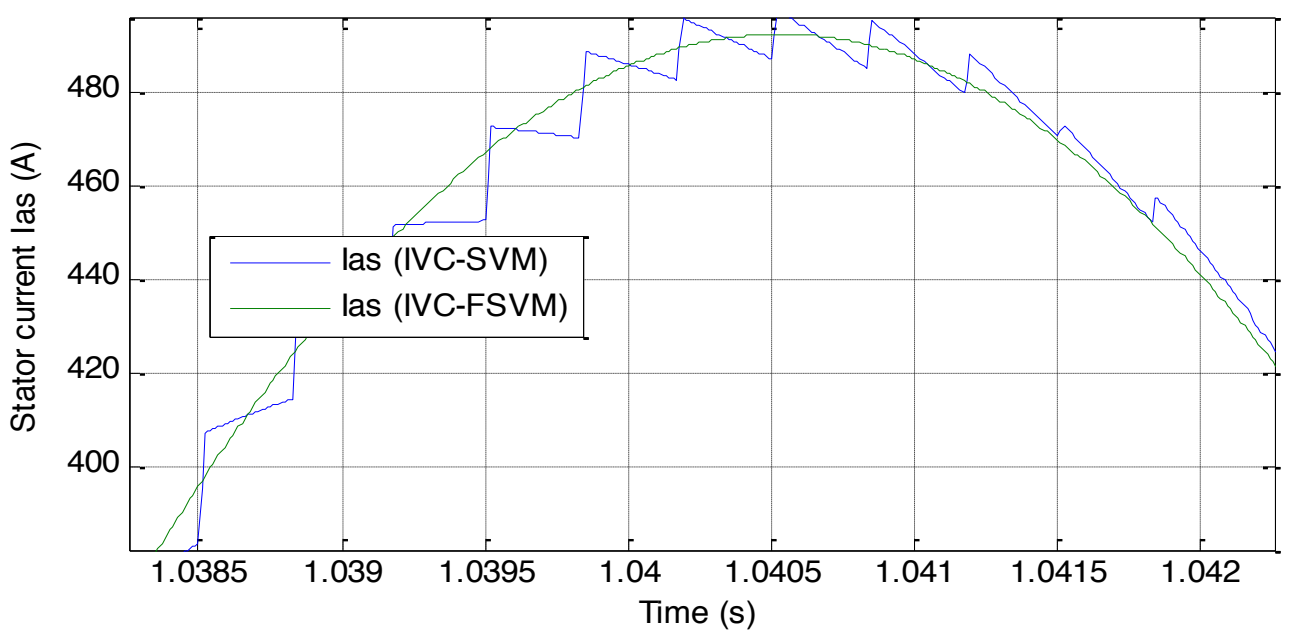

Fig. 16 Zoom in the stator current (reference tracking test). 


\subsection{Robustness test}

For analizing the robustness of the used IVC command schemes, the DFIG parameters have been intentionally changed sush as the values of the stator resistances $R_{s}$ are multiplied by 1.5 and the values of inductances $L_{s}$ are multiplied by 0.8 . Simulation results are presented in Figs 18-21. As its shown by these figures, these variations present a clear effect on the reactive power, active power, electromagnetic torque and current curves and that the effect appears more important for the IVC-SVM than that with IVC-FSVM method control.
On the other hand this results show that the THD value of stator current in the IVC-FSVM command scheme has been reduced significantly. Table 4 show the comparative analysis of THD value. Thus it can be finished that the proposed IVCFSVM command technique is more and more robust than the IVC-SVM one.

Table 4. Comparative analysis of THD value

\begin{tabular}{|c|c|c|}
\cline { 2 - 3 } \multicolumn{1}{c|}{} & \multicolumn{2}{c|}{ THD (\%) } \\
\cline { 2 - 3 } \multicolumn{1}{c|}{} & IVC-SVM & IVC-FSVM \\
\hline Stator current & 3.20 & 0.05 \\
\hline
\end{tabular}

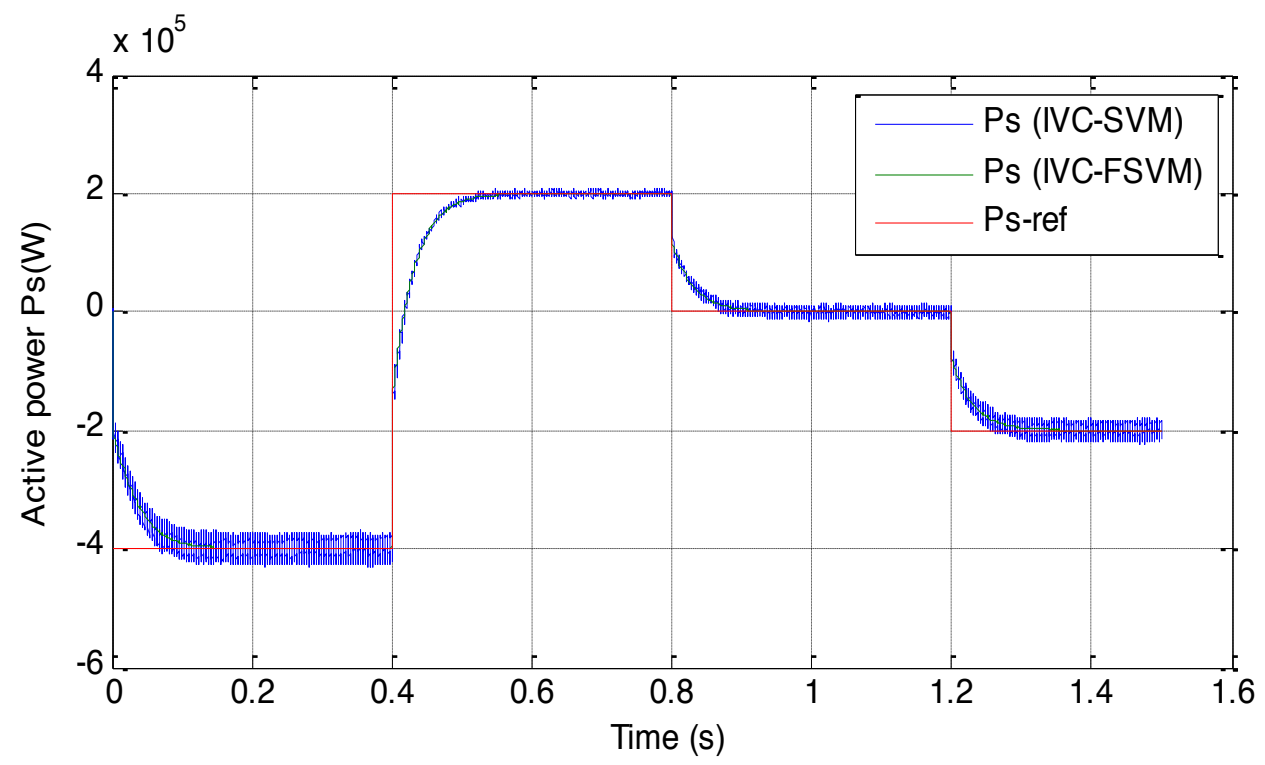

Fig. 17 Active power (robustness test).

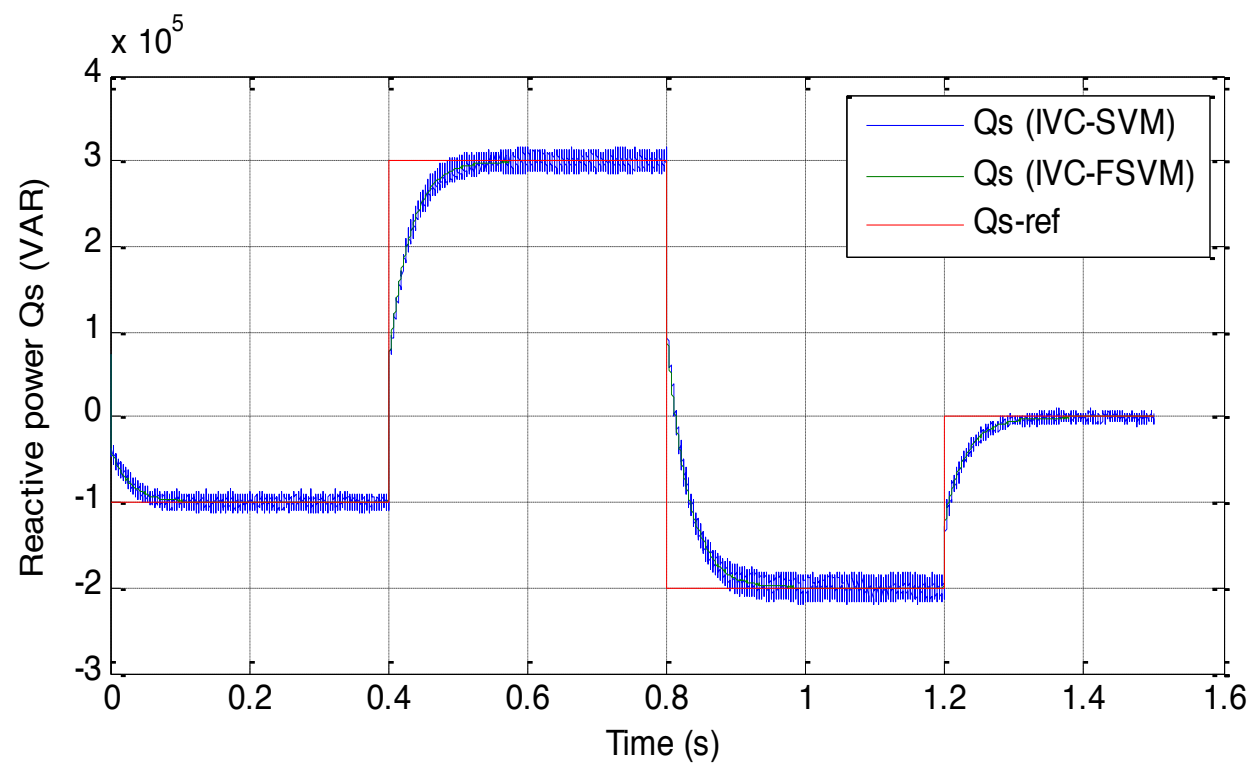

Fig. 18 Reactive power (robustness test). 
INTERNATIONAL JOURNAL Of SMART GRID

First Author et al., Vol.x, No.x, xxxx

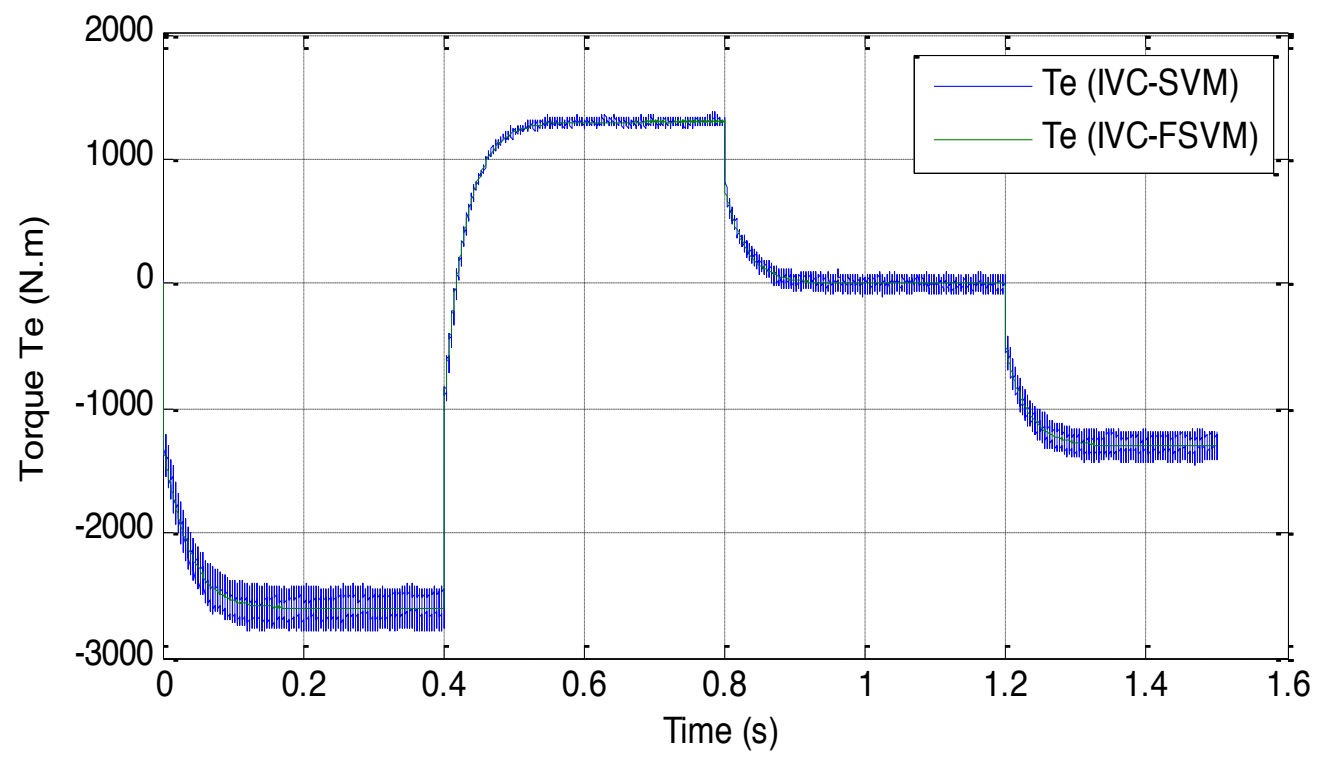

Fig. 19 Electromagnetic torque (robustness test).

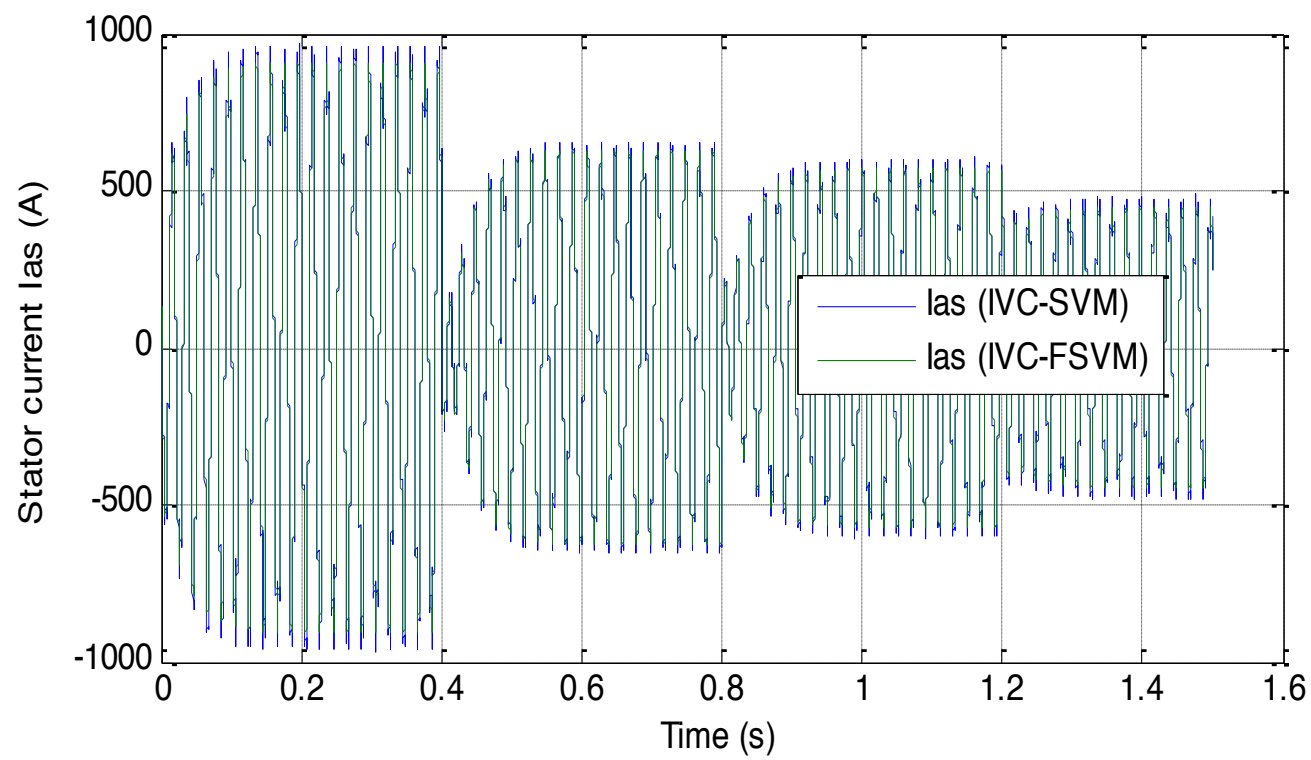

Fig. 20 Stator current (robustness test). 
INTERNATIONAL JOURNAL OF SMART GRID

First Author et al., Vol.x, No.x, xxxx
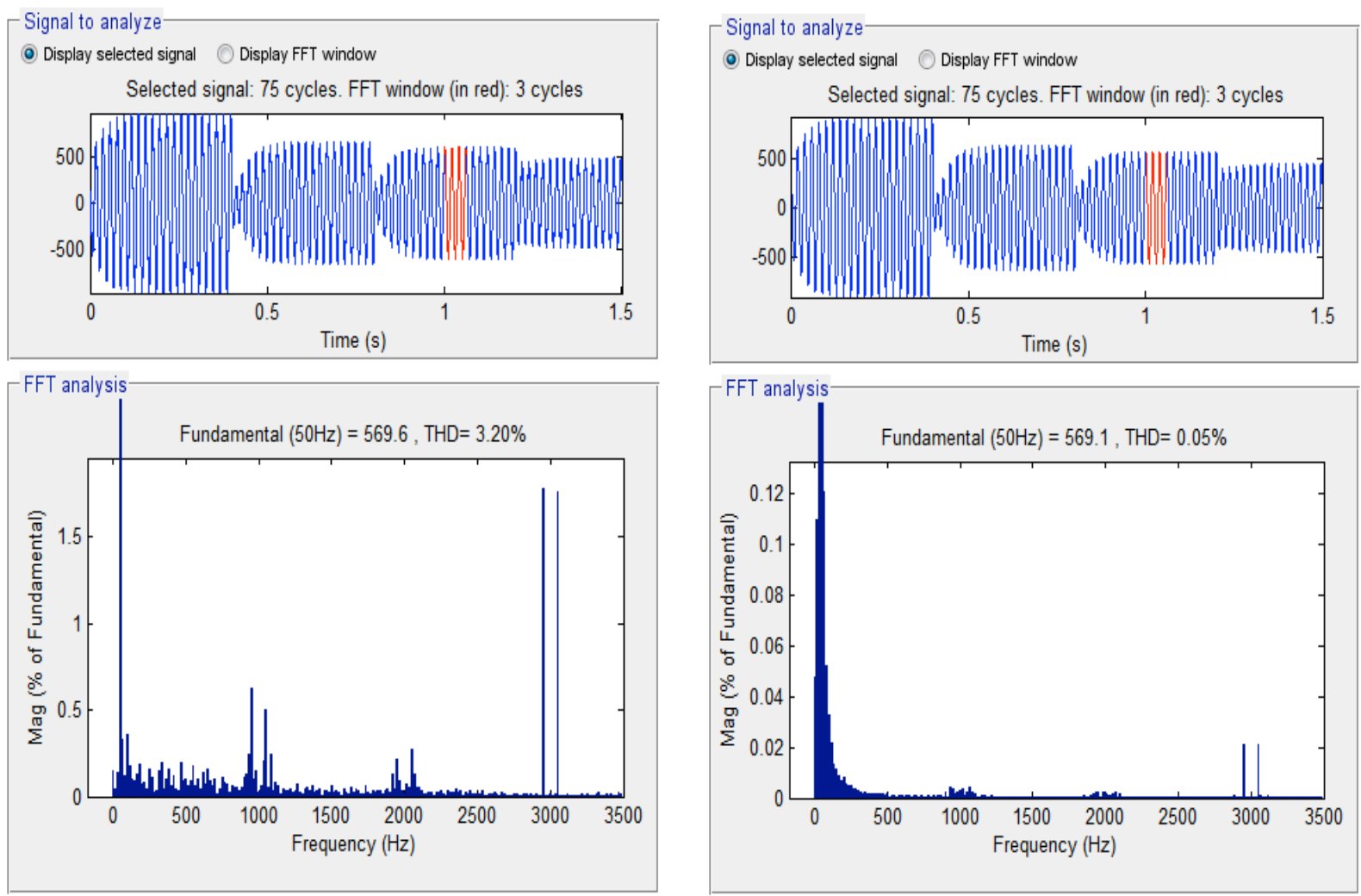

a)SVM-IVC

b) FSVM-IVC

Fig. 21 THD of stator current for a DFIG (robustness test).

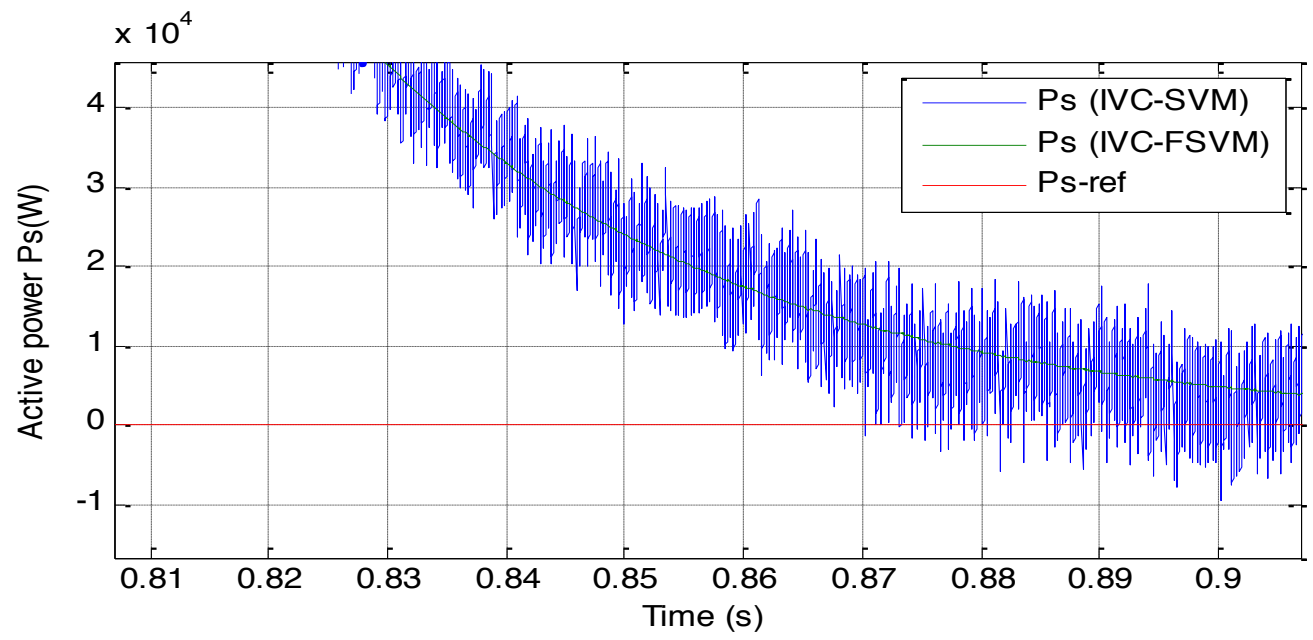

Fig. 22 Zoom in the active power (robustness test). 
INTERNATIONAL JOURNAL of SMART GRID

First Author et al., Vol.x, No.x, xxxx

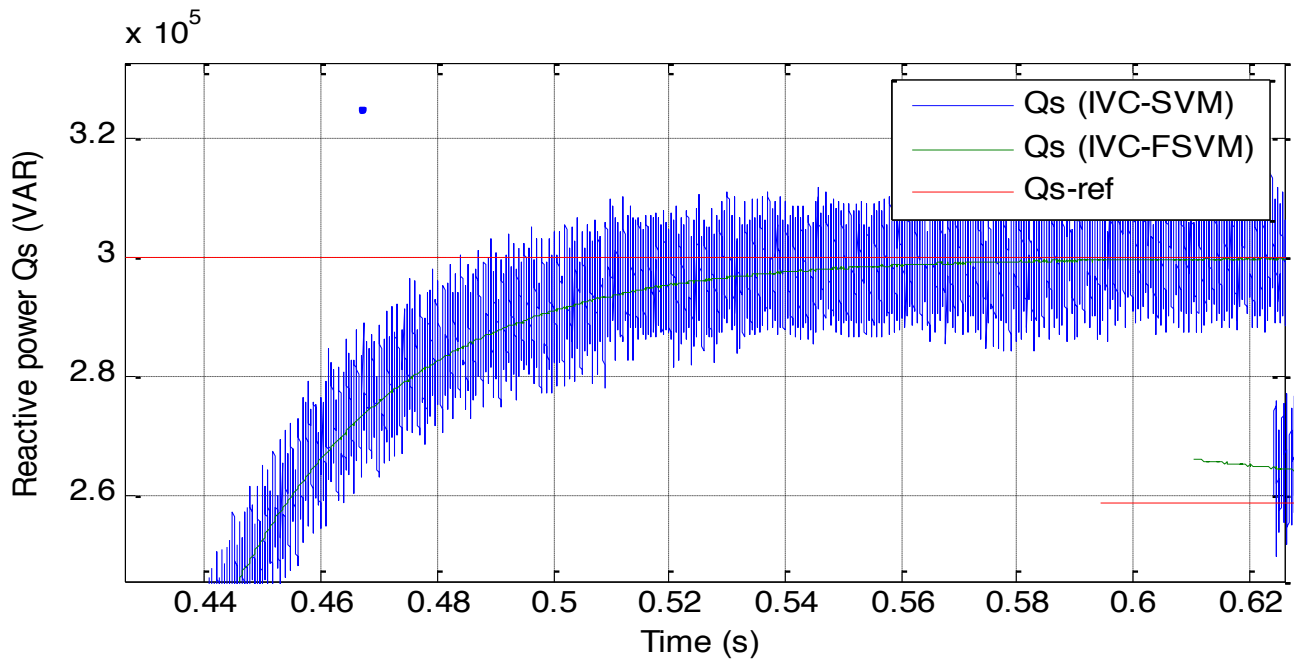

Fig. 23 Zoom in the reactive power (robustness test).

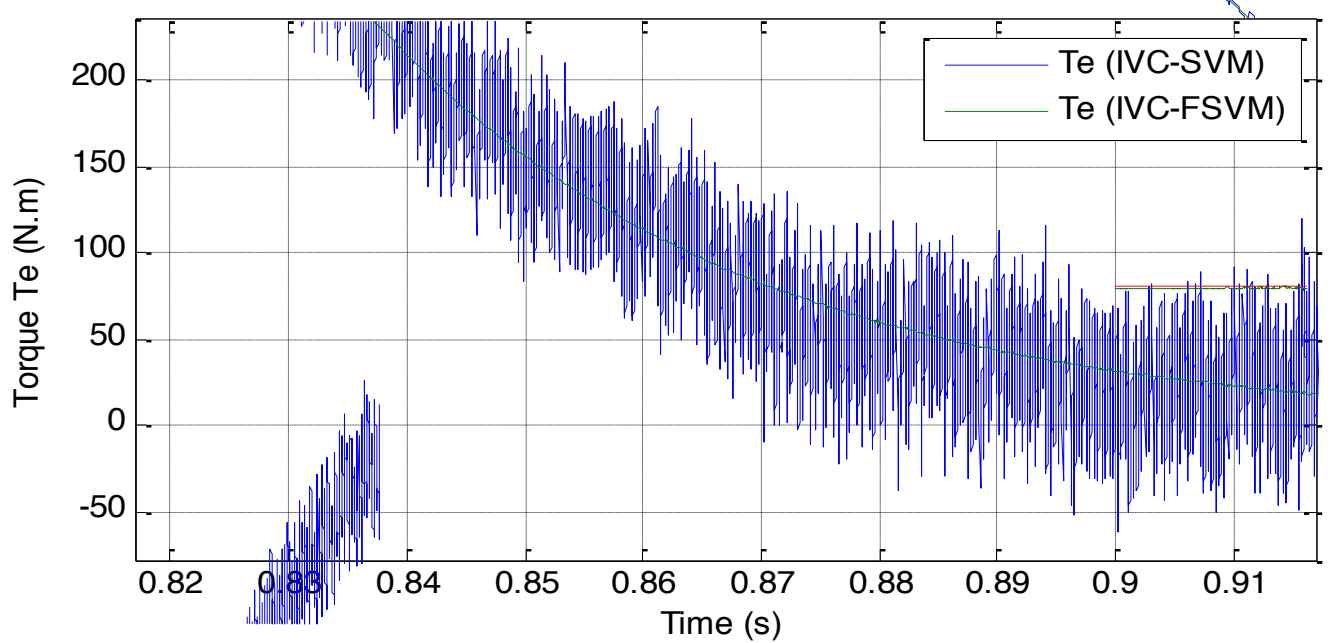

Fig. 24 Zoom in the torque (robustness test).

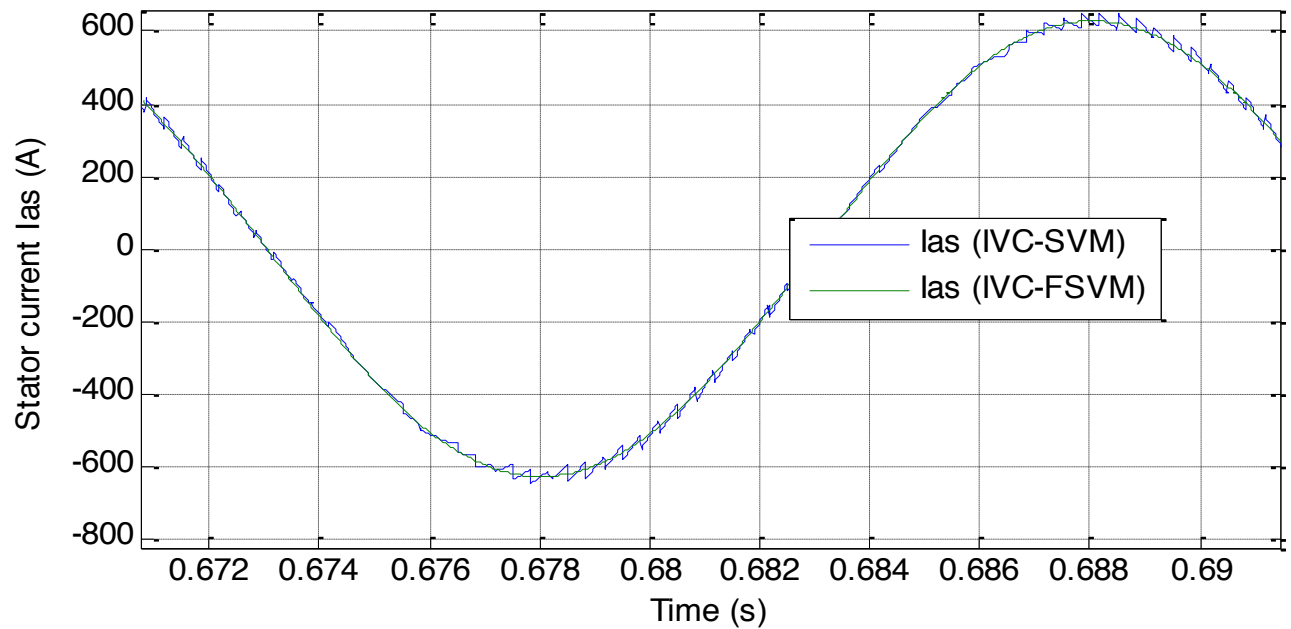

Fig. 25 Zoom in the stator current (robustness test). 


\section{Conclusion}

A new SVM technique of an IVC command scheme for a DFIG associated in a directly line to the grid by the stator area and fed by three-level NPC inverter from the rotor area has been presented in this article. The DFIG machine has numerous advantages as well as changeable speed process and the potential of action in four quadrants.

In this article, we proposed a novel SVM with fuzzy logic (FSVM) for command stator reactive and stator active powers and improved the performances of a DFIG machine by means of IVC command scheme. On the other hand, the IVC-FSVM is synthesized and compared to the IVC-SVM command. Simulation results have established that the proposed IVC-FSVM operates with a very lower ripples power and reduced of THD value in term the tracking test and robustness test. Basing on all these results it can be concluded that robust command schemes as IVC-FSVM can be a very good-looking result for strategy using DFIG such as wind power transfer systems.

\section{References}

[1] B. Hamane, M. L. Doumbia, M. Bouhamida, A. Draou, H. Chaoui, M. Benghanem, «Comparative study of PI, RST, Sliding mode and fuzzy supervisory controllers for DFIG based wind energy conversion system, " International Journal of Renewable Energy Research, Vol. 5, No. 4, pp. 1174-1184, 2015.

[2] Z. Boudjema, A. Meroufel, Y. Djerriri, « Nonlinear control of a doubly fed induction generator for wind energy conversion, » Carpathian Journal of Electronic and Computer Engineering, Vol. 6, No. 1, pp. 28-35, 2013.

[3] Y. Djerriri, A. Meroufel, A. Massoum, H. Hammoumi, «Using space vector modulation technique to improve direct power control strategy of doubly fed induction generator based wind energy conversion systems, » 7th International Conference on Electrical Engineering (CEE'12), 8-10 October 2012, University of Batna, Algeria.

[4] A. Tapia, G. Tapia, J. X. Ostalaza, J. R. Saenz, « Modeling and control of a wind turbine driven doubly fed induction generator, » IEEE Trans. On Energy Conversion, pp. 194-204, 2003.

[5] R. Chibani, E. M. Berkouk, M. S. Boucherit, «Fivelevel NPC-VSI capacitor voltage balancing using a novel clamping bridge, " Asian Power Electronics Journal, Vol. 5, No. 1, 2011.

[6] P. Rajasekaran, V. J. Senthilkumar, «An improved DTFC based five levels-NPC inverter fed induction motor for torque ripple minimization, » International Journal of Power Electronics and Drive System, Vol. 7, No. 2, pp. 531-542, 2016.
[7] M. Manivarma, J. Suyuna, P. Vimal Raj, " Comparison of savan level inverter with reduced number of switches and their Thd's in PI controller, » Journal of Electronics and Communication Engineering, pp. 32-42, 2016.

[8] Y. Bekakra, D. Ben Attous, «Comparison study between SVM and PWM inverter in sliding mode control of active and reactive power control of a DFIG for variable speed wind energy, » International Journal of Renewable Energy Research, Vol. 2, No. 3, pp. 471-776, 2012.

[9] E. Benyoussef, A. Meroufel, S. Barkat, « Three-level DTC based on fuzzy logic and neural network of sensorless DSSM using extende kalman filter, » International Journal of Power Electronics and Drive System (IJPEDS), Vol. 5, No. 4, pp. 453-463, 2015.

[10] A. Medjber, A. Moualdia, A. Mellit, M. A. Guessoum, « Comparative study between direct and indirect vector control applied to a wind turbine aquipped with a double-fed asynchronous machine Article, » International Journal of Renewable Energy Research, Vol. 3, No. 1, pp. 89-93, 2013.

[11]Z. Boudjema, A. Meroufel, Y. Djerriri, E. Bounadja, « Fuzzy sliding mode control of a doubly fed induction generator for wind energy conversion, » Carpathian Journal of Electronic and Computer Engineering, Vol. 6, No. 2, pp. 7-14, 2013.

[12]N. Khemiri, A. Khedher, M. F. Mimouni, «Wind energy conversion system using DFIG controlled by backstepping and sliding mode strategies, » International Journal of Renewable Energy Research, Vol. 2, No. 3, pp. 422-435, 2012.

[13] Y. Djerriri, A. Meroufel, B. Belabbas, A. Massoum, «Three-level NPC voltage source converter based direct power control of the doubly fed induction generator at low constant switching frequency, » Revue des Energies Renouvelables, Vol. 16, No. 1, pp. 91-103, 2013.

[14] A. Nazari, H. Heydari, «Direct power control topologies for DFIG-Based wind plants, » International Journal of Computer and Electrical Engineering, Vol. 4, No. 4, pp. 475-479, 2012.

[15]M. El-Azzaoui, H. Mahmoudi, K. Boudaraia, «Backstepping control of wind and photovoltaic hybrid renewable energy system, » International Journal of Power Electronics and Drive Systems, Vol. 7, No. 3, pp. 677-686, 2016.

[16] S. Krim, S. Gdaim, A. Mtibaa, M. F. Mimouni, «FPGA contribution in photovoltaic pumping systems : Models of MPPT and DTC-SVM algorithms, " International Journal of Renewable Energy Research, Vol. 6, No. 3, pp. 866-879, 2016. 
[17]A. Kocalims Bilhan, E. Akbal, « Modeling and simulation of two-level space vector PWM inverter using photovoltaic cells as DC source, » International Journal of Electronics, Mechanical and Mechatronics Engineering, Vol. 2, No. 4, pp. 311-317, 2012.

[18]A. Idir, M. Kidouche, « Direct torque control of three phase induction motor drive using fuzzy logic controllers for low torque ripple, » Proceedings Engineering \& Technology, Vol. 2, pp.78-83, 2013.

[19] M. M. Ismail, A. F. Bendary, "Protection of DFIG wind turbine using fuzzy logic control, » Alexandria Engineering Journal, Vol. 55, pp. 941-949, 2016.

[20]Z. Boudjema, A. Meroufel, E. Bounadja, Y. Djerriri, « Nonlinear control of a doubly fed induction generator supplied by a matrix converter for wind energy conversion systems, » Journal of Electrical Engineering (JEE), Vol. 14, No. 2, 2014.

[21] A. Bakouri, H. Mahmoudi, A. Abbou, « Intelligent control for doubly fed induction generator connected to the electrical network, " International Journal of Power Electronics and Drive System, Vol. 7, No. 3, pp. 688-700, 2016. 